\title{
CARTAS DE ZEAMI ENDEREÇADAS A ZENCHIKU
}

\section{Sakae Murakami Giroux}

Na vida há um fim; na arte de nô, o limite deve ser o infinito. (in KAKYó, O Espelho de uma Flor, 1424')

RESUMO: Tradução crítica das duas cartas de Zeami endereçadas a seu genro Zenchiku, uma datada provavelmente de sua residência de Quioto e outra de Sado, onde foi exilado pelo xogum Yoshinori. Segundo Omote, a primeira foi escrita por volta de 1428 e a segunda em 1435 quando Zeami já tinha se retirado da direção de companhia teatral Kanze. Essas cartas mostram que Zeami não cessou de orientar seu genro, chefe da companhia teatral Konparu, na arte de nô e revelam igualmente a estima recíproca entre esses dois artistas. São os únicos documentos da correspondência de Zeami que nos restam atualmente.

RÉSUMÉ: Traduction critique de deux lettres de Zeami à son gendre Zenchiku, l'une datée probalement de sa résidence de Kyôto et l'autre de l'île de Sado où le shôgun Yoshinori l'avait exilé. Selon Omote, la première aurait été écrite vers 1428 et la seconde en 1435, alors que Zeami avait déjà abandonné la direction de la compagnie Kanze. Ces lettres montrent que Zeami n'a jamais cessé de prodiguer ses conseils dans l'art du nô à son gendre, chef de la compagnie de théâtre Komparu, et révèlent également l'estime réciproque entre ces deux artistes. Ce sont les seuls documents qui subsistent aujourd'hui de la correspondance de Zeami.

PALAVRAS-CHAVE: Zeami, Nô, Teatro japonês, Correspondência de Zeami, Zenchiku. MOTS CLÉS: Zeami, Nô, Théâtre japonais, Correspondance de Zeami, Zenchiku.

1. Cf. A. Omote e S. Katô, "Kakyô", Zeami. Zenchiku, vol. 24 da coleção Nihon Shisô Taikei, p. 108. 
Konparu Ujinobu, de nome búdico Zenchiku, foi o décimo terceiro chefe da mais antiga companhia teatral de nô de Yamato, Enmai-za, posteriormente denominada Konparu-za.

A genealogia da família Kanze, Kanshi kafu ${ }^{2}$, informa que Zenchiku casou-se com a filha de Zeami, o segundo chefe da companhia teatral de nô Kanze-za, igualmente da região de Yamato. Como as transmissões secretas de uma arte ocorriam, geralmente, entre membros de uma mesma família ou pessoas próximas a ela, estima- se que Zenchiku já era genro de Zeami quando este último lhe transmitiu, em 1428, os tratados teatrais Rikugi (Os Seis Modos) e Shûgyoku tokka (Recolher as Jóias, Esperar a Flor).

A relação entre esses dois artistas foi excelente. Zeami acompanhou de perto a formação artística de seu genro ${ }^{3}$ talvez porque o considerasse o único capaz de preservar o caminho de sua arte: é o que, em todo caso, ele nos faz comprender em uma das passagens do tratado Kyakuraika ( $O$ Ir e o Vir da Flor), onde via em Zenchiku um futuro mestre consagrado ${ }^{4}$. Motomasa, filho primogênito e herdeiro de Kanze-za morrera subitamente durante uma turnê na província de Ise, em 1432.

As duas únicas cartas que nos restam escritas por Zeami a Zenchiku ${ }^{5}$ - uma ainda de sua residência de Quioto e outra da ilha de exílio, Sado - comprovam a grande estima que existia entre eles. Zenchiku, mesmo depois de Zeami ter se retirado da cena teatral, mesmo após ser exilado pelo xogum Yoshinori, continuava considerando-o mestre de sua arte e também um pai, ajudando-o, inclusive materialmente, na sua penúria. Zeami, por sua vez, mesmo de seu exílio, privado da família e de sua companhia teatral, continuava transmitindo suas experiências de nô a Zenchiku, esperando ver concretizado, através dele, a continuidade de sua arte.

E de fato, Zenchiku não decepcionou seu mestre: seu trabalho de ator foi respeitado pelos conhecedores de nô; suas peças, como as de Zeami, privilegiavam o canto e a dança, destacando a elegância sutil e a sobriedade de seus personagens; e seus tratados, embora não representassem a continuidade teórica de Zeami, pois tinham outra natureza reflexiva ${ }^{6}$, receberam fortes influências do pensamento de Zeami, principalmente os desenvolvidos no Kyâi (Os Nove Niveis) e Shûgyoku tokka.

2. Esta genealogia foi compilada por Asano Eisoku, entre o fim do século XVIII e início do século XIX.

3. Zenchiku elegeu Zeami como seu mestre, em parte porque não conheceu seu tio Konparu Gonnokami, personagem citado no capítulo XXI de Zeshi rokujî̀ igo sarugaku dangi (Considerações sobre Sarugaku com Zeshi após seu Sexagésimo Aniversário) e, em parte, porque seu pai Mitsutarô ou foi um artista medíocre ou teve uma morte prematura. Não há nenhuma referência a este último nos tratados de Zenchiku.

4. Cf. A. Omote e S. Katô, "Kyakuraika", op. cit., p. 246. Esta passagem revela igualmente que Motomasa tinha um grande respeito por Zenchiku.

5. O conteúdo dessas duas cartas prova que outras correspondências foram trocadas entre Zeami e Zenchiku. Por exemplo, através dos escritos de Konparu Ujitsuna, pode-se saber que até os meados da época Edo (fim do século XVIII), existia uma outra carta de Zeami transmitida na família Konparu que se iniciava com a frase: "recebi esta carta com grande alegria..."; entretanto, hoje não se tem mais notícias dessa missiva que deve ter desaparecido com o passar dos anos (cf. A. Omote e S. Katô, Zeami. Zenchiku, p. 571).

6. Os tratados de Zeami, salvo raras exceçōes, transmitiam a seus sucessores o savoir faire do nô, baseando-se na própria experiência do artista ao passo que os de Zenchiku tentavam explicar a essência desta arte chamada nô, fundamentando-se nas diferentes teorias emprestadas da poesia e do budismo. 
Traduzimos, neste estudo, as duas cartas que foram conservadas na família Konparu e que constam da coleção Nihon shisô taikei, vol. 24, Zeami. Zenchiku, organizado por Omote Akira e Katô Shûichi.

/ Carta datada do décimo quarto dia do quinto mês ${ }^{7}$ /

Endereçada ao Senhor Konparu

Em mãos

De Kia

Zea

\author{
Alma que capta \\ a ignorância d'alma, \\ qual outra jóia perceberá? ${ }^{8}$
}

Li com grande atenção vossa missiva. Assim, pude me inteirar do fato de que descereis ${ }^{9}$ para a província do Norte e vos felicito. Entretanto, no que me concerne, sinto-me desamparado em saber que partireis para tão longe ${ }^{10}$. Por outro lado, recebi /vossa solicitação/ sobre /a avaliação de vosso/ nô. Quanto a vossa qualificação enquanto shite ${ }^{11}$, como vos disse, concederei minha permissão ${ }^{12}$ o mais breve possível. Dora-

7. Carta endereçada a Zenchiku a partir de Kia (bairro de Quioto?). Não se tem certeza do ano em que ela foi redigida. Omote estima que tenha sido alguns anos após 1428 (ano 1 da era Chôchô), ano em que Zeami transmitiu o tratado Shûgyoku tokka: Colher as Jóicus, Transmitir a Flor, a Zenchiku. Cf. A. Omote e S. Katô, op. cit., p. 316.

8. Sodegaki ou otsutegaki, isto é, palavras acrescidas na margem direita da missiva. O sodegaki em questão é um poema e seu último verso termina com uma pergunta retórica (hango). Prespõe-se, portanto, uma resposta negativa, ou seja, não existe nenhuma outra jóia mais importante do que o reconhecimento de sua própria ignorância, de seu próprio limite.

9. Ou seja, partir da capital para a província. Pelo contexto, pode-se supor a expansão do sucesso de Zenchiku por outras regiōes além daquelas já conhecidas.

10. Nessa época, Motomasa, filho primogênito e herdeiro da arte de Zeami ainda se encontrava, provavelmente, em plena atividade artística. Esta passagem revela, portanto, não só a grande estima mas também a confiança que Zeami já sentia em Zenchiku.

11. Zenchiku deve ter solicitado ao mestre Zeami a aprecią̧ão e o reconhecimento de seu nível de arte enquanto shite (chefe e ator principal) de sua companhia teatral Enmai-za (ou Takeda no za). Esta escola, que foi posteriormente denominada Konparu-za, sobrevive ainda hoje junto com Hôshô-za, Kongô-za, Kanze-za, todas da região de Yamato da época Muromachi (século XV) e com Kita-za, fundada na época Edo (século XVII).

12. O capítulo XXV de Zeshi rokujû igo sarugaku dangi trata dos sonhos onde apareciam as revelações divinas. Ali Motoyoshi narra que a filha de um carpinteiro de cascas de cipreste, moradora das redondezas de Shôkoku-ji (Quioto), gravemente doente, no décimo nono dia do décimo primeiro mês do ano 29 da era Ôei (1422), teve, em sonho, uma revelação da divindade Kitano que exigia , em troca de sua cura, poemas de exortação que obtivessem notas de aprovação de Zeami (cf. S. M. Giroux, Zeami: Cena e Pensamento Nô, pp. 245-246). Esta e outras história sobre a força quase divina de Zeami eram freqüentes no meio teatral do sarugaku de Yamato, o que comprovava o respeito que tinham seus companheiros de arte por Zeami. Portanto, embora Zenchiku já fosse chefe de uma companhia teatral e um ator bastante requisitado, conseguir uma carta de aprovação ou permissāo de Zeami significava, sem dúvida, a "consagração universal" de sua arte. 
vante, tudo dependerá de vossa disposição de espírito ${ }^{13}$ O senhor Miura ${ }^{14}$ me disse que assistiu, em Ômi ${ }^{15}$, a vossa representação de nô. Ele me afirmou que vossa arte progrediu consideravelmente. Como seus olhos são exercidos /para bem avaliar a arte de nô / não duvido dessas palavras e sinto-me totalmente confiante. Entretanto, considerando que nem mil testemunhas valem um só olhar, darei minha apreciação final somente após ter visto, eu mesmo, vossa interpretação. Desde que me assegure de vossa qualidade na arte, tereis meu consentimento ${ }^{16}$. No que se refere à prática da Lei de $\mathrm{Buda}^{17}$, o segundo Abade de Fuganji ${ }^{18}$ ensina que a prática ${ }^{i 9}$ de um mestre equivale aos estudos que se seguem à aquisição dos arcanos ${ }^{20}$. Assim, vosso nô deve possuir, sem dúvida, um notável conhecimento desses arcanos. Quanto às mãos ${ }^{21}$, utilizai-as em grandes ondas, retendo na alma a assimilaçāo, pelos olhos e pelos ouvidos, dos dois elementos e três tipos ${ }^{22}$. E ainda mais e mais, tanto quanto for possível, vos será neces-

13. Refere-se a shin' $i$, nível de arte que atinge a esfera do espírito, ou seja, "a força mental que liga, pela unidade do espírito, os dez mil meios de expressão" (cf. A. Omote e S. Katô, "Kakyô", op. cit., p. 100).

14. Personagem sem referência biográfica, talvez um artista de nô do sarugaku de Ômi.

15. Embora as companhias teatrais do sarugaku de Ômi tenham desaparecido com o passar dos anos e sua tradição totalmente interrompida, na época de Kan'ami e Zeami esse sarugaku se encontrava em plena atividade, com grandes sucessos. Mesmo o xogum Yoshimitsu, que foi um defensor incondicional da companhia Kanze, parecia, no fim de sua vida, preferir a arte de Inuô de Ômi que interpretava seus personagens acentuando o yûgen, o charme sutil. Mesmo Zeami confessava ter sido influenciado por esta representação. Mas Inuô, por sua vez, venerava Kan'ami que, através de sua arte, abriu caminho para possibilidade de sucesso a todos os atores de sarugaku, ultrapassando a arte de dengaku que dominava, até então, a cena artística. Conta o capítulo XXI de Sarugaku dangi que, em cada décimo nono dia do mês, dia da morte de Kanami, Inuô recomendava um serviço religioso em memória daquele que o tinha conduzido à glória (cf. S. M. Giroux, op. cit., p. 237). Desta forma, a base da relação entre o sarugaku de Yamato e de Ômi sempre foi de grande respeito mútuo, fato que podemos também perceber nesta carta de Zeami.

16. Essa reticência de Zeami mostra, de um lado, o rigor de um mestre e, de outro, o receio em dar sua aprovação, talvez porque considerasse que $a$ arte de Zenchiku não tinha ainda o nível que atingisse uma "consagração universal" Para Zeami, como mostra o texto Museki isshi (Traço de um Sonho sobre uma Folha), redigido em memória do filho Motomasa, em 1432 (portanto na mesma época em que foi redigida esta carta, se aceitarmos a teoria de Omote), o único artista que podia defender a linhagem de seu sarugaku era justamente Motomasa (cf. A. Omote e S. Katô, "Museki isshi", op. cit., p. 242). E ainda, no tratado Kyakuraika (O Ir e o Vir da Flor) que traz o posfácio datado do terceiro mês do ano 5 da era Eikyô, ou seja, 1433, Zeami considerava imaturo o nô de seu genro afirmando que Zenchiku possuía uma arte correta mas que era necessário continuar persistindo no caminho do sarugaku para, com a idade e a experiência, ser considerado, um dia, um mestre consagrado (cf. A. Omote e S. Katô, "Kyakuraika", op. cit., p. 236).

17. Budismo zen. Em seus tratados teatrais, Zeami se serviu de terminologias búdicas, notadamente da corrente zen para transmitir os exercícios de nô a seus herdeiros como, por exemplo, kyakurai ou kôko kyakurai : o retorno. O zen ensina que num verdadeiro caminho de Buda, o iluminado deve "retornar" a este mundo a fim de guiar aqueles que se encontram ainda nas trevas. Zeami diz no tratado Kyâi que apenas um mestre consagrado pode "retornar" aos níveis inferiores para dar a "flor" ao personagem demônio.

18. Chikusô Chigon, abade de segunda geração do templo Fuganji do departamento de Nara, parte quase central da região onde estavam localizadas as companhias teatrais do sarugaku de Yamato (cf. A. Omote e S. Kato, op. cit., nota 179, p. 505).

19. Refere-se aos estudos de zen.

20. Pode-se ler também "a iluminação".

21. Esta frase responde a uma questão precisa de Zenchiku sobre a interpretação.

22. Os dois elementos, nikyoku, indicam o canto e a dança e os três tipos, santai, o anciāo, a mulher e o guerreiro, três tipos-base do nô. O canto e a dança constituem os primeiros exercícios da vida do ator de 
sário, através da repetição de exercícios, acumular vossa experiência, mesmo que já tenhais penetrado /na compreensão dos/arcanos. Sem vos descuidar um só momento, conservai na alma a prática dos exercícios de um mestre. Em todas as coisas, tenhai em mente somente o vosso nô. Disseram-me que desde o vosso nô /da épocal de Tamba ${ }^{23}$, fizestes notáveis progressos e que sois, vós mesmo, consciente/do fato/. É o que o Senhor Miura também diz ter constatado, assistindo /a vossa interpretação/. Uma terceira pessoa que me dizia ter vos visto na representação em benefício de estabelecimentos religiosos ${ }^{24}$ em Kawachii $^{25}$, elogiou vivamente /vossa arte/. Desta forma, sem sombra de dúvida, estou totalmente convencido de que vosso nô progrediu. E considerando também o fato de terdes penetrado previamente nos arcanos, estimo que atingistes o nível da consagraçāo universal. Todavia, repito, mil testemunhas não valem um só olhar. /Portanto/, somente quando tiver apreciado vosso nô pessoalmente poderei vos dar uma resposta definitiva.

\section{Respeitosamente,}

Décimo quarto dia do quinto mês

Zea / sinete /

Ao Mestre Konparu-dayû, em resposta

\section{/ Carta datada clo oitavo dia do sexto mês /}

\section{Endereçada ao Mestre Konparu-dayû}

$\mathrm{Zea}^{26}$

E mais e mais, vosso zelo

seja /por minha esposa/ em minha ausência,

seja /por mim/ em meu exílio,

- palavras são poucas para vos agradecer ${ }^{27}$

Li com atenção vossa missiva. Ainda quando mal tive tempo de vos agradecer suficientemente pela atenção que tendes dispensado a Jushin ${ }^{28}$, /desde meu exílio em Sado/ até hoje, vós

nô e ele terá a permissão de se iniciar nos estudos dos três tipos (portanto da mímica) somente após ter assimilado e dominado todas essas técnicas.

23. Distrito de origem da companhia de Zenchiku.

24. Kanjin sarugaku, representaçōes que se faziam ao ar livre em cenas especialmente concebidas para tal evento. Era um local de encontro onde todas as camadas sociais se reuniam para assistirem à arte dos grandes mestres. $O$ ingresso era pago o que significava uma entrada considerável para o caixa das companhias teatrais. Esse fato, sem dúvida, acirrava a competição entre as companhias para se incluírem nessas representações onde apenas os mais destacados na arte e na relação com os detentores do poder tinham participações asseguradas. Assim, esta passagem comprova que Zenchiku e sua companhia teatral possuía uma posição confirmada no meio teatral de nô.

25. Onde a companhia de Zenchiku teve grandes atividades teatrais.

26. Parte escrita no envelope da carta com sinete, enviada de Sado, ilha de seu exílio. Não consta do documento o ano de sua redação. Omote é de opinião de que foi redigida no segundo ano do exílio, ou seja, no ano sete da era Eikyô (1435) e de que esta carta não devia ter sido a primeira enviada do exílio para Zenchiku (cf.A. Omote e S. Katô, op. cit., pp. 318-319).

27. Sodegaki acrescida na margem direita da carta.

28. Esse nome é considerado como sendo o da esposa de Zeami. 
estendeis essa ajuda até a mim e graças a vós, posso, nessa província ${ }^{29}$, passar os meus dias sem me preocupar com os olhos externos ${ }^{31}$. E ainda, os dez kanmon ${ }^{31}$ /que me enviastes/ eu bem os recebi. Se, por ventura, um dia me for permitido o retorno à Capital, e aí puder vos encontrar, espero ter convosco momentos de longas confidências ${ }^{32}$. Por outro lado, li em vossa missiva uma pergunta sobre o /personagem / demônio. Este é um tema /bastante/ desconhecido em nossa escola ${ }^{33}$. Excluindo os três tipos / de base ${ }^{34} /$, /nossa escola/ considera, ao todo, até /o personagem do/ estilo de movimento detalhado ${ }^{35}$. Outros /personagens/ como os do estilo de movimento violento ${ }^{36}$ é

29. Zeami, no ano seis da era Eikyô (1434), com setenta e dois anos, foi exilado para ilha de Sado, por ordem de xogum Yoshinori. O motivo da punição é desconhecido pois Zeami não faz referências nem mesmo no Kintôsho ( $O$ Livro da Ilha de Ouro), uma crônica de sua viagem para Sado. Mas várias suposiçōes foram formuladas pelos estudiosos de Zeami e a mais verossímil parte da informação contida no Shiza yakusha mokuroku (Registro sobre Atores de Quatro Companhias), segundo a qual Zeami foi exilado por ter preferido Zenchiku ao próprio filho. Por esse "filho" deve-se entender On'ami Motoshige, sobrinho adotivo de Zeami e ator preferido do xogum Yoshinori pois nessa época o primogênito Motomasa estava morto e o caçula Motoyoshi já tinha se retirado da vida artística para vestir o hábito. É também verdade que Zeami transmitiu os tratados teatrais a Zecnchiku, pelo menos dois deles (Rikugi e Shûgyoku tokka) e nenhum a On'ami.

30. Para Zeami, homem de teatro que fez da elegância e sutileza a essência de sua arte, os "olhos externos" significariam também os ollos do público e, portanto, manter a postura até o fim de suas forças era uma necessidade vital. Nesse sentido, a ajuda não só moral mas também material de Zenchiku deve ter sem dúvida facilitado a Zeami essa tarefa.

31. Valor monetário da época. Um kanmon equivaleria aos mil mon (cf. A. Omote e S. Katô, op, cit., p. 318).

32. As informações que nos restam sobre o final da vida de Zeami são escassas e nem se sabe se ele pôde voltar a Quioto. Fora as que constam desta carta, sabe-se apenas que sua morte ocorreu aos oitenta e um anos, no oitavo dia do oitavo mês.

33. No livro II de Fûshikaden (Da Transmissão da Flor de Interpretação) que trata das indicações sobre a mímica, Zeami abre um grande parágrafo para falar sobre o demônio: considera que ele faz parte de um repertório particular da escola de Yamato e que é um personagem difícil de interpretar. No livro $\mathrm{V}$ deste mesmo tratado que estuda os arcanos de nô,. Zeami compara o estilo de Yamato com o de Ômi ressaltando que o primeiro coloca em suas representações um destaque à mímica, enquanto que o segundo, ao charme sutil. No Fûshikaden a presença do nô da época de Kan'ami é forte, especialmente até o livro cinco, pois em seu posfácio Zeami escreve que ele é um simples depositário dos ensinamentos de seu pai. (cf. A. Omote e S. Katô, op. cit., pp. 25, 42 e 46). É evidente que nesta afirmação há uma certa dose de exagero uma vez que percebemos, já neste primeiro tratado, uma certa inclinação de Zeami pelo nô sutil, mais próximo à representaçāo de Ômi do que a de Yamato.

34. Os nove tipos de Fûshikuden, a mulher, o ancião, o personagem de rosto descoberto, o demente, o monge, o ashura, o deus, o demônio e os personagens de assuntos chineses, foram reduzidos no tratado Nôsakusho ( $O$ Livro da Composição de Nô) para os três tipos de base, a mulher, o ancião e o guerreiro; esse procedimento indica o caminho de Zeami em busca da essência dos tipos representados, num processo artístico de interiorização da técnica de representação do $n \hat{o}$.

35. No tratado Ningyô (Figuras Humanas), Zeami descreve o saidô (o movimento detalhado) como o estilo que pertence ao personagem "demônio pelo aspecto mas homem pelo espírito"; assim, sua interpretação não requer nenhuma violência, nem do espírito, nem do corpo. Ele define o haturaki como o estilo ideal do movimento detalhado e afirma que, de acordo com as circunstâncias, o espírito saidô pode ser encontrado nos papéis de ancião, de homem jovem, de menino e mesmo de mulher demente (cf. A. Omote e S. Katô, "Ningyô", op. cit., p. 121).

36. No mesmo tratado Ningyô, Zeami descreve o rikidô (movimento violento) como o estilo do "demônio pela força, pelo aspecto e pelo espírito". Assim, o efeito visual obtido por este personagem é totalmente árido e suas atitudes são desprovidas de todo "interesse". Esse estilo poderia, eventualmente, ser interpretado entre vários outros das diferentes peças, à guisa de finalização, com o objetivo de reter a 
praticado em outras escolas ${ }^{37}$. Somente quando, de vez em quando, meu falecido pai interpretava o demônio ${ }^{38}$ e expressava, através do canto, uma força próxima à deste personagem, aprendíamos/ imitando-o /. Mesmo eu, só ousei tentar interpretá-lo depois de ter entrado na vida religio$\mathrm{sa}^{33}$. Sou de opinião que é somente com uma idade avançada e com toda a experiência adquirida aos fios dos anos que podemos, inclusive os senhores e todos aqueles que abraçaram o caminho do nô, nos permitir aventurar a interpretar um demônio e, esse preceito, devemos guardá-lo no fundo de nossas almas ${ }^{40}$. De resto, as coisas que vos prometi há um certo tempo, anotarei em grandes linhas e fá-las-ei chegar em vossas mãos; assim, dispensai a maior das atenções em sua leitura ${ }^{41}$. /Na penúria/ inimaginável desta longínqua província ${ }^{42}$, me é mesmo impossível encontrar um papel apresentável e assim vós deveis julgar que é uma inconsequiência minha escrever /sobre os preceitos de nô / em uma folha como esta. Entretanto, muito embora o espírito do Caminho e as regras da prática da Sublime Lei tenham sido traçados por um pincel

atenção do público por um só momento pois ele agride os olhos e excita os espíritos. Todavia, é um estilo que não admite nenhuma repetição (cf. "Ningyô", A. Omote e S. Katô, op. cit., p. 129).

37. No tratado Kyâii (Os Nove Graus), onde Zeami enumera os nove estilos segundo os níveis superior, intermediário e inferior, os saidô e rikidô são considerados como estilos pertencentes ao nível inferior. Essa classificação nada tem de excepcional se considerarmos que a base da estética zeamiana é o yûgen que destaca a elegância, a sutileza e o charme de seus personagens.

38. Basta analisar a peça Jinen kôji composto por Kan'ami para nos certificarmos que seu nô era dinâmico apoiando-se bem mais na mímica. Dentro desta lógica, o demônio tinha lugar assegurado no repertório e para Kan'ami, interpretá-lo não devia ter sido tão problemático quanto o foi para Zeami.

39. No capítulo XXIV de Sarıgaku dangi, na passagem sobre a doença da filha de carpinteiro em 1423 (vide nota 7), há indicação de que nesta época Zeami já tinha se retirado do meio mundano para vestir o hábito; portanto ele interpretou o demônio apenas após seus cinquienta anos.

40. No primeiro tratado Fûshikaden, Zeami chama a atenção de seus discípulos para a interpretação extremamente difícil do personagem demônio pois, se a força e o horror são as características essenciais desta mímica, a junção desses dois elementos excluem todo o sentimento de "interesse". Nessas condições, um ator capaz de despertar o "interesse" do demônio será, sem dúvida, aquele que já possui uma habilidade consumada, ou seja, que já possui a "flor" do nô. Um jovem ator poderá, talvez, interpretá-lo corretamente mas esse correto seria desprovido de todo o "interesse". Ora, atribuir o "interesse" ao demônio, segundo Zeami, seria procurar um efeito artístico semelhante à eclosão de uma flor sobre um recife. No tratado Kyâi, por outro lado, Zeami situa a mímica do demônio entre os estilos do nível inferior e diz que apenas um artista de talento que seguiu o caminho do nô, iniciando seus exercícios a partir dos níveis intermediários, ascendendo, em seguida, aos níveis superiores e descendo, finalmente, aos níveis inferiores, é capaz de produzir, no demônio, um efeito visual de alta qualidade (cf. "Fûshikaden" e "Kyûi", A. Omote e S. Katô, op. cit., pp. 26 e 177). Por outro lado, os comentários de Zeami sobre o demônio contidos nesta carta indica que Zenchiku desconhecia, pelo menos parcialmente, o conteúdo dos tratados acima citados. Portanto, se Kyâi foi transmitido a Zenchiku como deduzem os especialistas, talvez tenha sido uma versão incompleta deste tratado.

41. Zenchiku provavelmente pediu orientação de Zeami sobre outros pontos precisos relativos à interpretação e essa passagem indica claramente uma frequiente troca de correspondência entre eles. Após a morte de Motomasa, para não interromper o caminho de sua arte, Zeami parece ter escolhido Zenchiku como o sucessor de sua arte, embora fosse chefe de uma outra companhia. Desta forma, Zeami coloca em prática o que ele afirma no final do tratado Fûshikaden: "Que seja ele seu próprio filho, evitai transmitir esses ensinamentos a um incapaz. Dizem: Não é pelo parentesco, é pela sucessão das tradições que se constitui uma linhagem. Não é pelo berço, é pelo saber que se forma o homem. Este princípio deve levar a uma perfeição total a flor maravilhosa de dez mil virtudes" ("Fûshikaden", A. Omote e S. Katô, op. cit., pp. 64-65).

42. No tratado Kintôsho redigido em 1436, Zeami denomina essa província longínqua desprovida de todo o brilho a que estava tão acostumado, de Kintô, ou seja, a llha de Ouro. 
de palha, considerai esse pobre papel onde foram depositados os sublimes ensinamentos do caminho da arte como se fosse uma folha de ouro. Queirai-vos, portanto, fazer de vosso melhor para respeitar a Lei.

$$
\text { Respeitosamente, }
$$

Oitavo dia do sexto mês

Zeô / sinete /

Ao Mestre Konparu-dayû

\section{Bibliografia}

Giroux, Sakae Murakami. Zeami: Cena e Pensamento Nô. Estudos n. 122, São Paulo, Perspectiva / Aliança Cultural Brasil-Japão, 1991, 376 p.

OMOTE, Akira e SHÛICHI, Katô.Zeami. Zenchiku. In Nihon shisô taikei tomo 24, Tóquio, Iwanami shoten, 1974, 584 p.

Sakae Murakami Giroux

Départment des études japonaises Université de Strasbourg II (France)

22, rue Descartes

67084 Strasbourg cedex email: giroux@ushs.u-strasb.fr 